that it is only with those dangers which attend mortification that we have to deal because with this imperfect hernia comes a tumor. The only case that I have met was an old man of 76 in whom there was a tumor the fourth day afterward. The symptoms of strangulation are not constant, but may approach shock. It is important to detect this in time, and 1 believe the condition referred to in the paper is much more common than is generally supposed.

Dr. Miles F. Porter of Indiana-I know that this condition does occur and occurs acutely, for I remember a case occurring in a female child twenty-two months old. The diagnosis was made and operation revealed a Littre's hernia with strangu lation.

Dr. G. G. Davis of Philadelphia--I remember an old lady about sixty years of age who was brought into the hospital after having suffered with symptoms of strangulated hernia for about ten days. I thought it was a Littre's hernia of a por tion of the intestinal wall, and in the diverticulum. On oper ation I found there was a cancerous body embracing one quarter of the circumference of the gut and about one inch long. This pointed definitely to the fact that a partial strang ulation of the gut itself occurred, and goes to show that the only history is one of length and not acute.

Dr. SMrTH-The fact that we have symptoms of strangulated hernia with the passage of gas has been proven. We sometime incline to err because the existing symptoms are not compatible with the conditions. It is important for every one to appre ciate the fact that whenever a hernia is strangulated it should either be reduced easily and promptly, or treated by operation. The danger from the operation is very much less than from the excessive use of taxis. Having this additional danger brought before us today, it is very likely to save many a patient from excessive taxis.

Dr. J. McFadden Gaston of Atlanta, Ga.-I saw four cases of this particular kind of hernia before I recognized the character of the trouble, and in three of them I succeeded in reduction by taxis. The evidence was very conclusive of the existence of the hernia. In one case I used taxis to a considerable extent, under anesthesia. After letting the patient rest, and using asefedita and belladonna. I was able to reduce it by taxis. I was called in consultation in another case in which we all agreed that it was a case of obstruction of the bowel of some form and we agreed that possibly it might be an indurated gland. The symptoms all pointed to bowel obstruction, however, and we treated upon this principle. The case went on to the point when there was an indication of liquid formation and fecal extravasation, death ensuing. I thought we would find a partial dislocation of the intestine, which was verified.

Dr. E. TAPPEY of Detroit, Mich.-As to the condition of the intestine in the first diagram that was shown, in a Littre's hernia, a portion of the intestinal wall becomes herniated and my conception is that there is necessarily a formation of an angle on the opposite wall of the hernia. I suppose that if the intestine gets into the position shown in the diagram, it must be that the hernia has become chronic and adhesions have formed. The intestine becomes distended, but I do not think that this condition can exist in an acute condition. I have seen this condition of Littre's hernia where a portion of the intestine had become herniated in the median line just below the diaphragm.

Dr. E. D. Ferguson of Troy-My observations in these cases have been where the hernial protrusion has been much drawn out of the usual sites. I wish to speak of one point in the management of the case. Usually when we have hernias of this kind and succeed in reducing them, we must take into consideration the extreme liability of adhesions in the intestinal cavity. The wisest surgical procedure would be to proceed at once to the obliteration of the hernia canal.

Dr. BurNs of Long Island City -1 have had one case with symptoms of intestinal obstruction, although it was not considered by the doctor in attendance that the hernia accounted for the symptoms. I was called in and examined all the points referring to the possibility of hernia. There did not seem to be enough of importance to warrant us in saying what it might be and we removed the patient to the hospital to operate on her. During the operation I opened a sac and introduced my finger to examine it when $I$ found that something had sunk back from the inguinal canal. I found the inguinal glands quite free. I concluded to close the canal and we decided not to explore with a further incision in this particular case. The symptoms became better after the operation and in ten days the patient left the hospital. I kept her on a suitable diet and there was some slight rise of temperature. We let her leave the hospital in a spring wagon, and she traveled about one and a half miles on a country road. Upon arriving home she ate a German dish and I was called to see her a few hours afterward, when she died suddenly. My personal conviction was that she had omental hernia, but I am now convinced that she had a hernia of the kind mentioned today. I was very sorry that an autopsy could not be secured. I remember another case of a similar nature in a very stout woman. I had no proper apparatus for operation but I concluded to operate. I succeeded in replacing it through the natural aperture and she was able toleave off her truss which she had been wearing for a long time.

Dr. HATCH of Quincy, Ill.-There is a class of cases which can be very easily mistaken for obstruction to the bowels. I mean the class where there is a partial incrustation of the in testine. In these cases you will find attachments around the coating of the intestines which simulate incrustations, and you will also find that, on the sides of the intestine, the feces are in batches, leaving but a small opening, so that you have all the symptoms of an obstruction and some of those of a hernia, with intense pain. Such was the case that $I$ saw, and I had one of the same kind about a month ago. By the application of warm fowentations and small repeated doses of calomel I was able to remove all but a few incrustations around the intestinal wall.

Dr. STAHL - So far as the meaning of a Littre's hernia is concerned, it is mentioned to a considerable extent in French literature. Our friend from Detroit tells us that he had a case above the umbilicus, and Littre's second case was just such a one. This was the chronic form, which my own case must have been. My own case was purely a case of intestinal wall bernia. Littre's first hernia was one of Meckel's ganglia. We have two appendices in poultry, and when we have a Meckel's ganglia it is a very similar thing. This is well shown by the mesentery in poultry. The American Text-Book shows that, in the treatment of a Littre's hernia, we must understand hernias of all the parts of the diverticulum, whether congenital or acquired. So far as the term is concerned we must still use it as he first described both the congenital and the acquired forms. There are other forms which I have not been able to bring out. The only object that I have in presenting this paper is to state what is not usually well known, that the whole intestinal wall is not drawn out. Whether the case is congentital or acquired is important, and hard to decide.

It is not an infrequent form of hernia. If we can prove that the acute form does occur we will then have broughi much credit upon our meeting.

\section{A NOVEL METHOD FOR THE USE OF DRY HEAT IN THE MIDDLE EAR DIS. \\ EASE, OTALGIA, ETC.}

Presented in the Section on Laryngology and Otology, at the Fortyeighth Annual Meeting of the American Medical Association, beld at Philadelphia. June 1-4, 1897.

BY E. LARUE VANSANT, M.D.

PHILA DELPHIA, PA.

The local use of dry heat has long been justly regarded as a valuable therapeutic agent in treating inflammations of the ear, otalgia, etc.; these applications in the form of hot salt and bran bags, or hot water bottles, however, are usually only made to the external ear, the actual amount of heat, therefore, coming in contact with the external auditory canal and membrana tympani is necessarily slight. It has often occurred to me, while treating various forms of ear diseases, that the direct application of heated dry air to the drumhead and middle ear would be desirable, provided we had an apparatus whereby the degree of heat could be regulated, and by the aid of which it could be readily obtained and applied. I have now such an apparatus, having found it to answer the desired purpose. It is a modification of an instrument which was first devised for the purpose of dental surgery. It consists of a metallic bulb or barrel containing a piece of carbon, a rubber hand-ball aircompresser, and a long curved pointed steel nozzle. The bulb (or barrel) is heated sufficiently by being held over a flame, preferably that of a spirit lamp; a current of air is then forced through it by means of the hand ball, thus delivering a small stream of heated 
air from the nozzle of the instrument, which is directed against the spot which is to be treated. The degree of heat produced can be regulated by the length of time the bulb is held over the flame and also by the distance between the mouth of the nozzle and the surface toward which the heat is directed. The original instrument I have modified by making the nozzle straight instead of curved and by attach. ing a handle so that the air from a compressed air reservoir can be used. In applying the heated air to the ear, a hard-rubber speculum may be used through which the current of air is directed.

I have used heated dry air applied in this manner in quite a large number of cases representing various forms of ear disease, and can recommend this instrument in suitable cases.

In otalgia of all forms, by its aid I have usually succeeded very promptly in relieving the suffering of the patient.

In the so-called dry treatment of otorrhea, I have found it a valuable adjunct. My method of applying the dry treatment is to thoroughly remove the secretion with sterilized cotton, then dry the moist surfaces with heated air and follow this by insuffluting a powdered medicament. The heated air used in this manner was found to be very grateful to the patient; it not only dries the middle ear but I have frequently noticed that it seemed to drive out some retained gas.

In the sharp recurring pains that frequently follow the rupture of the drumbead during an acute otitis media, the applicution of the hot air has given almost instani relief. "I have not used the method in many cases of acute otitis media, but when $I$ have done so the patients were considerably relieved from pain.

The effect of a hot air current upon the course of an acute otitis media is a matter to be determined by further experience. In chronic purulent otitis media I have noticed a decided stimulation of the mucous membrane and an increase of reparative action.

In treating catarrhal conditions of the Eustachian tube and middle ear, the heated air may be directed through a hard-rubber Eustachian catheter. I have also used the treatment in a number of throat and nasal diseases, and I am able by means of a long curved hard-rubber nozzle, to force heated air into the trachea and perhaps even lower into the air passages. It is my intention, however, to make this the subject of a later communication.

1929 Chestnut Street.

DISCUSSION.

Dr. Max Thorner-I have seen the device of Dr. Vansant and think it good, though I have not used it. Dry heat externally is always very grateful in middle ear troubles, and I do not see why dry heat internally should not be still better.

Dr. RandaLL-The novel element in this is the dryness of the air. I have known that heated vapors were better than cold vapors. The apparatus of Hubbard is really a repetition of Hartman's inatrument of some five years ago, which has met with very little success. I shall try this method with great interest.

Dr. MarshaLl - I think hot air would be a distinct help if it could be made sterile.

Dr. VANSANT - In my very brief paper I purposely refrained from citing cases. I hope that members will give the method a trial, and by experience find out its value. In using the instrument, especially with the compressed air reservoir, if you get ton close the heat is too intense. It should be given in little puffs instead of a steady application. The instrument requires delicate manipulation. I think it may also be found of value in tinnitus due to Eustachian trouble. The instru. ment is used by dentists, and it is claimed that it lessens the pain in filling the teeth.

\section{A FEW OBSERVATIONS OF SOME EAST. ERN EUROPEAN TOWNS AND HOSPITALS. \\ BY CASEY A. WOOD, M.D. CHICAGO.}

The disputed question as to the whereabouts of the largest hospital in the world will be decided in a year or so when the great Ospedale Romana is completed. This enormous establishment was begun in 1893 and hus already cost many millions of live. It will inclose within its limits, in northeastern Rome, all the various public hospitals, dispensaries, laboratories and clinics now scattered over the Imperial city. Instead of numerous isolated institutions, most of them housed in old, insanitary and dingy quarters, there will be but one collection of clean, well built, well drained, well ventilated, well lighted pavilions, replete with all the appliances, and provided with all the improvements that distinguish the modern hospital. On the other hand. the present father of hospitals, the great Allgemeines Krankenhaus at Vienna, grows more and more out-at-the-elbows, down-at-the-heels and baggy-at-the-knees. Nobody has better reason than the writer to appreciate how much the whole profession owes those alicient buildings in the Josephstadt, but surely the time has come for a change, not only in the nursing methods that have so long prevailed there, but in the old microbeladen walls themselves - a thought suggested by contemplation of the recent hospital erections that almost every small town in Europe and America seems to be making in response to the demand for absolute cleanliness on the part of everything and everybody who enters hospital doors.

When the city hospital in Rome is ready for occupation it will afford ample facilities for study and if a liberal policy be pursued toward foreigners, the Italian capital will make a most attractive and profitable center for medical study and may divert to itself some of that large stream of students that for so many years has been steadily flowing toward Vienna. The work done by Italians in all departments of medicine and surgery deserves to be better known than it is. Moreover, the language, spoken, written and printed, is much more easily learned by Americans than is German, especially when the student has been assisted by a previous acquaintance with more or less French or Latin. In the province of ophthalmology and otology, with which the writer is most conversant, it may be suid with truth that not to know enough ltalian for translation purposes is to miss almost as much as not to be able to read French. Certain it is that the medical schools of Pavia, Turin, Rome, Naples and Palermo all have well informed ophthrilmologists and otologists attached to them whose activities are of a kind by no means inferior to the best effiort of the professors in German, American and French universities.

Although we found Athens in a state of general war depression, the hospital service seemed good in all its appointments. There is an ophthalmic hospital of considerable size for a city of 200,000 , that is to say, its dispensary department is largely attended and it has twenty-four beds for indoor patients. Professor Anagnostakis, who had for years beld the foremost place in Greek ophthalmology, having just died, I was indebted to the courtesy of Dr. Georgios Gazepy for my news. Although the limestone dust 